\title{
Mucor racemosus IgG4 Measurement
}

National Cancer Institute

\section{Source}

National Cancer Institute. Mucor racemosus Ig G4 Measurement. NCI Thesaurus. Code C130099.

A measurement of the Mucor racemosus IgG4 in a biological specimen. 